\title{
C-type natriuretic peptide stimulates function of the murine Sertoli cells via activation of the NPR-B/CGMP/PKG signaling pathway
}

\author{
Yuejin Yu\#, Yao Chen\#, Chunlei Mei, Na Li, Kejia Wu and Donghui Huang ${ }^{\varpi}$ \\ Institute of Reproductive Health, Tongji Medical College, Huazhong University of Science and Technology, Wuhan 430030, China
}

C-type natriuretic peptide (CNP) is an important regulator of the male reproductive process. Our previous investigations showed that CNP can significantly stimulate the mRNA expression of androgen-binding protein (Abp) and transferrin (Trf) in the rat Sertoli cells, but the pathways responsible for this process remain to be elucidated. We predict that CNP binds the natriuretic peptide receptor B (NPR-B) to regulate expression of ABP and TRF through the intracellular cyclic guanosine monophosphate (cGMP) pathway. To address this question, in this study, we first confirmed the expression and localization of CNP and NPR-B in rat testes by immunohistochemistry and western blotting. Then, ELISA and real-time PCR were performed to investigate the signaling pathway of CNP in Sertoli cells in rat testes. Our results showed that CNP was mainly localized in the germ cells and Leydig cells, and its receptor, NPR-B, was mostly expressed in the Sertoli cells and vascular endothelial cells. CNP supplementation in the Sertoli cell medium was accompanied by an increase in the amount of intracellular cGMP and in the production of Abp and Trf mRNA, whereas inhibition of PKG with KT5823 led to a decrease in the expression of Abp and Trf mRNA. Moreover, Abp and Trf mRNA were no longer elevated when we used liposome-mediated RNA interference technology to silence the NPR-B gene in a mouse Sertoli cell line (TM4). These results suggest that CNP contributes to the regulation of $A B P$ and TRF in the Sertoli cells through the NPR-B/ cGMP/PKG signaling pathways.

Keywords: C-type natriuretic peptide; natriuretic peptide receptor-B; Sertoli cell; cyclic GMP

Received: 04 August, 2020; revised: 10 January, 2021; accepted: 11 January, 2021; available on-line: 08 July, 2021

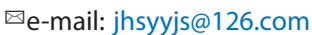

\#Yuejin Yu and Yao Chen contributed equally to this study

Acknowledgments of Financial Support: This work was supported by the National Natural Science Foundation of China (No. 81771575) and the Independent Innovation Foundation of Tongji Medical College of Huazhong University of Science and Technology (No. 0118519028).

Abbreviations: Abp, androgen-binding protein; Trf, transferrin; Npr-b, natriuretic peptide receptor- $B$

\section{INTRODUCTION}

The natriuretic peptide family in mammals mainly consists of four structurally related peptides: atrial natriuretic peptide (ANP), brain natriuretic peptide (BNP), C-type natriuretic peptide (CNP) and D-type natriuretic peptide (DNP) (Moghtadaei et al., 2016). As the third member of the natriuretic peptide family, the C-type natriuretic peptide (CNP) was initially purified in 1990 from por- cine brain extracts for its ability to relax smooth muscle (Sudoh et al., 1990; Xia et al., 2013). In contrast to ANP and BNP, which are both cardiac hormones (Baba et al., 2019), CNP is regarded as an endothelin and plays its role through specifically binding the membrane-bound natriuretic peptide receptor B (NPR-B) via intracellular cyclic guanosine monophosphate (cGMP) activation (An et al., 2019). The literature has shown that CNP is involved in mediating a variety of physiological effects, such as the regulation of myocardial contractility (Prickett et al., 2017), cell proliferation (Zenitani et al., 2016), endochondral ossification (Bükülmez et al., 2014), and reproduction (Zhang et al., 2010). Sogawa and others (Sogawa et al., 2014) created an NPR-B deficient male mouse model with short limbs and dwarfism, which turned out to be infertile, with pathological sections that indicated a puberty spermatogenesis delay, but its mechanism was unclear.

The Sertoli cells are somatic cells in seminiferous tubules that play an extremely important role in maintaining a subtle testicular microenvironment. They are the main element of the blood-testis barrier (Smith \& Braun, 2012), and synthesize and secrete androgen-binding protein (ABP), transferrin (TRF) and other important functional proteins to regulate the process of spermatogenesis (Ma et al., 2015). ABP is a glycoprotein produced by the Sertoli cells that specifically binds to testosterone, which enables spermatogenesis in the seminiferous tubules and sperm maturation in the epididymis (Chinta et al., 2015). TRF, secreted by the Sertoli cells, is an important marker of its function, providing essential iron for spermatogenic cells (Dietrich et al., 2010). Xia et al. (2007) reported that CNP could perturb the Sertoli cell tight junctions, causing the disappearance of the bloodtestis barrier-associated proteins (JAM-A, occludin, Ncadherin and $\beta$-catenin) from the cell/cell interface. Our previous investigation showed that CNP could significantly stimulate in vitro cultured Sertoli cells to express Abp, inhibin B (Inh-b) and Trf, which play a key role in spermatogenesis (Huang et al., 2011).

This study was designed to elucidate the signal transduction of CNP in Sertoli cells. Furthermore, there is no literature about the regulation of the endocrine function of Sertoli cells through cGMP signal transduction.

\section{MATERIALS AND METHODS}

\section{Animals}

Male Sprague-Dawley rats were obtained by the Laboratory Animal Centre of Tongji Medical College, Huazhong University of Science and Technology (Wu- 
han, China). They were raised under controlled environmental conditions $\left(22 \pm 2{ }^{\circ} \mathrm{C} ; 12 \mathrm{~h}\right.$ light $/ 12 \mathrm{~h}$ dark cycle; $35-60 \%$ relative humidity) with food and water ad libitum. This study was approved by the Centre of Experimental Animals of Huazhong University of Science and Technology (no. 42009800001411, 10-10-2015) and conducted in the reproductive immunology laboratory at the Reproductive Health Institute of Tongji Medical College.

\section{Immunohistochemical detection of CNP and NPR-B in rat testes}

Testes collected from adult male Sprague-Dawley rats were used to analyze the localization of CNP/NPR-B by an immunohistochemical staining method. Briefly, the testicular tissue was fixed in the Bouin's acid for $24 \mathrm{~h}$ and then processed for routine paraffin embedding. Paraffin sections were dewaxed in xylene and rehydrated through descending concentrations of ethanol, and then endogenous peroxidases were blocked with $3 \% \mathrm{H}_{2} \mathrm{O}_{2} /$ methanol. The sections were preincubated with nonimmune rabbit serum to minimize nonspecific staining. After that, the testicular tissue was incubated with primary rabbit polyclonal antibody against CNP (sc-20952, 1:50) and goat polyclonal antibody against NPR-B (sc-16870, 1:50) (Santa Cruz Biotechnology Inc., Santa Cruz, CA), and then incubated with a biotinylated secondary antibody (rabbit anti-goat IgG 1:200, Boster Biotechnology Co., Ltd., probed, Wuhan, China) and the streptavidinbiotin-peroxidase complex (Boster Biotechnology Co. Ltd., Wuhan, China) according to the manufacturer's instructions. Peroxidases were observed with a diaminobenzidine reagent, and the sections were briefly counterstained with hematoxylin. Negative controls were prepared without the primary antibody. The experiment was repeated three times.

\section{Isolation of the Sertoli cells and Leydig cells}

Primary rat Sertoli cells were isolated and cultured as previously described (Huang et al., 2007). Briefly, testes from 18- to 22-day-old SD rats were removed, decapsulated, chopped and sequentially digested with three enzymes at $37^{\circ} \mathrm{C}$ : first with $0.25 \%$ trypsin for 15 minutes, then with $0.1 \%$ hyaluronidase for 30 minutes, and finally with $0.1 \%$ collagenase $\mathrm{V}$ for $2-3$ hours. The isolated cells were incubated at $32^{\circ} \mathrm{C}$ in a humidified atmosphere of $5 \% \mathrm{CO}_{2}$. To increase the purity of the Sertoli cells, the cultured cells were subjected to a hypotonic shock (treatment) with $20 \mathrm{mmol}$ Tris- $\mathrm{HCl}$ after 48 hours of incubation. The cultured cells were identified by Feulgen staining and in situ hybridization with digoxin-labeled rat ABP cDNA. More than 95\% of the cultured cells were Sertoli cells.

Primary rat Leydig cells were isolated and cultured as follows (Zhou et al., 2016). Briefly, testes from adult SD rats were removed and decapsulated, and then placed in DMEM-F12 containing $0.25 \mathrm{mg} / \mathrm{mL}$ collagenase with constant agitation. The supernatant containing Leydig cells was filtered through a double layer of $100 \mu \mathrm{m}$ nylon mesh and collected by centrifugation. The Leydig cell suspension was loaded on top of a discontinuous Percoll gradient $(5 \%, 30 \%, 58 \%$ and $70 \%)$ and then centrifuged. After centrifugation, most of the purified Leydig cells were observed in the third Percoll gradient. These Leydig cells were carefully collected and washed two times. The isolated cells were incubated at $37^{\circ} \mathrm{C}$ in a humidified atmosphere of $5 \% \mathrm{CO}_{2}$. The cultured cells were identified by $3 \beta$-hydroxysteroid dehydrogenase ( $3 \beta$-HSD) staining. Approximately $90 \%$ of the cultured cells were Leydig cells.

\section{Protein extraction and western blot analysis}

The total proteins of testes, cultured Sertoli cells and Leydig cells were extracted using a radioimmunoprecipitation assay lysis buffer according to the manufacturer's recommendation. Concentrations of proteins were estimated by an enhanced BCA protein assay kit (P0010). Equal amounts of proteins were separated on $10 \%$ SDSPAGE gels and transferred onto polyvinylidene fluoride membranes. The immunodetection of NPR-B was performed with the use of NPR-B goat polyclonal antibody (diluted at 1:200) and a secondary antibody conjugated with HRP (diluted at 1:5000). The reactive bands were detected by an enhanced chemiluminescence system using X-ray film. The immunoreactive bands were analyzed as two-dimensional images using ImageJ (version 1.32). The results are expressed as the mean \pm S.D. from three independent experiments.

\section{Measurement of intracellular cGMP levels}

Before experiments, the cells were pretreated overnight in a serum-free medium. Subsequently, the Sertoli cells in the experimental groups were incubated with different concentrations $\left(10^{-7} \mathrm{~mol} / \mathrm{L}, 10^{-6} \mathrm{~mol} / \mathrm{L}\right)$ of CNP (N8768, Sigma-Aldrich, St. Louis, MO, USA), and the control group was incubated with an untreated medium. After $2 \mathrm{~h}$ treatment, cGMP was extracted from adherent cells by treatment with $0.1 \mathrm{M} \mathrm{HCl}$. Samples were stored at $-80^{\circ} \mathrm{C}$ before measurement of cGMP levels. cGMP concentrations were measured by a rat cGMP ELISA kit (JL11179, Jianglai Biology, Shanghai, China,) according to the manufacturer's protocol. The results are expressed as the mean \pm S.D. from three independent experiments.

\section{RNA isolation and RT-qPCR}

Purified Sertoli cells were incubated in the presence of CNP, 8-Br-cGMP (cell-permeable cGMP analog 8-bromoguanosine 3',5'-cyclic monophosphate), CNP + KT5823 (PKG inhibitor) or PBS (control) at the same time for $2 \mathrm{~h}$, and then the treated cells were harvested to analyze gene expression levels of Abp and Trf using RT-qPCR. Total RNA from purified Sertoli cells was isolated using TRIzol reagent (Life Technologies, Gaithersburg, MD) following the protocol recommended by the manufacturer. Total RNA concentration and purity were determined spectrophotometrically. To eliminate residual genomic DNA, RNA samples (3 $\mu \mathrm{g}$ of total RNA) were treated with 1 IU of DNase-I in a $10-\mu$ l reaction mixture. After DNase-I treatment, $3 \mu \mathrm{g}$ of total RNA from each sample were reverse transcribed into first-strand cDNA in a $20-\mu l$ reaction mixture containing $0.5 \mu \mathrm{g}$ of oligo(dT) $)_{18}$ primer, $1 \times \mathrm{RT}$ buffer, $1 \mathrm{mM} \mathrm{dNTP}$ Mix, $20 \mathrm{U}$ of RiboLock RNase Inhibitor and $200 \mathrm{U}$ of RevertAid M-MuLV Reverse Transcriptase according to the supplier's instructions.

cDNA samples were subjected to real-time qPCR (Roche LightCycler 480 Real-Time PCR), which was performed as previously described (Huang et al., 2011). The primer pairs used in RT-PCR are listed in Table 1. An aliquot of $5 \mu \mathrm{l}$ of the RT reaction was amplified with the PCR reagent system in a final volume of $50 \mu \mathrm{l}$ containing $1 \times$ Taq Buffer, $3 \mathrm{mM} \mathrm{MgCl}, 0.2 \mathrm{mM}$ dNTP Mix, $0.2 \mu \mathrm{M}$ primers (Table 1), $1.25 \mathrm{U}$ of Taq DNA polymerase and $0.2 \times$ SYBR Green I. The amplified products were analyzed by $2 \%$ agarose gel electrophoresis and vis- 
Table 1. Sequences of primers used in the RT-PCR analysis

\begin{tabular}{|c|c|c|c|}
\hline Gene & Forward primer & Reverse primer & Length (bp) \\
\hline$\beta$-actin & $5^{\prime}$ TCC TCC CTG GAG AAG AGC TA 3' & 5' TCA GGA GGA GCA ATG ATC TTG 3' & 302 \\
\hline$r-A b p$ & 5' ATC AGC AAA CCC TCT TCC CTC 3' & 5' AGG CAT AGC ATC TCT CTT TTC C 3' & 263 \\
\hline$r-T r f$ & 5' CCA AGC TCC AAA CCA TGT TGT 3' & 5' GCA GGC TTC TAG GAG TCG TGA 3' & 283 \\
\hline$N p r-b$ & 5' ССАААТТСТАССССАСТСТG 3' & 5' TAAGAAGTGTCACCACCTGC 3' & 183 \\
\hline
\end{tabular}

Abbreviations: Abp, androgen-binding protein; Trf, transferrin; Npr-b, natriuretic peptide receptor-B.

ualized with ethidium bromide. The results are expressed as the mean \pm S.D. from three independent experiments.

\section{TM4 cell transfection}

Due to the low transfection efficiency of the rat primary Sertoli cells, we chose the mouse Sertoli cell line TM4 (CRL-1715) for the transfection experiment. The mouse Sertoli cell line TM4 was purchased from ATCC. The cells were inoculated with approximately $1 \times 10^{5}$ cells per well in 24-well plates, and $0.5 \mathrm{ml}$ of medium per well was added. The next day, when the cells reached $70-90 \%$ confluence, the transfection experiment was completed following Invitrogen's Lipo-2000 protocol. Briefly, $5 \mu$ l of Lipo-2000 reagent was diluted in $50 \mu \mathrm{l}$ of Opti-MEM, $5 \mu \mathrm{g}$ of DNA was diluted in $50 \mu \mathrm{l}$ of OptiMEM, and the diluted DNA and Lipo-2000 reagent (1:1 ratio) were combined. The mix was incubated for 5 minutes at room temperature, then the DNA-lipid complex was added to the cells for an incubation period of $48 \mathrm{~h}$ at $37^{\circ} \mathrm{C}$. Four shRNA interference sequences purchased from the OriGene company (Catalog No: TG712192) were chosen and designed to screen for the most effective shRNA to silence the NPR-B gene. The cultured cells without shRNA were regarded as the control. The four sequences of shRNA are listed in Table 2.
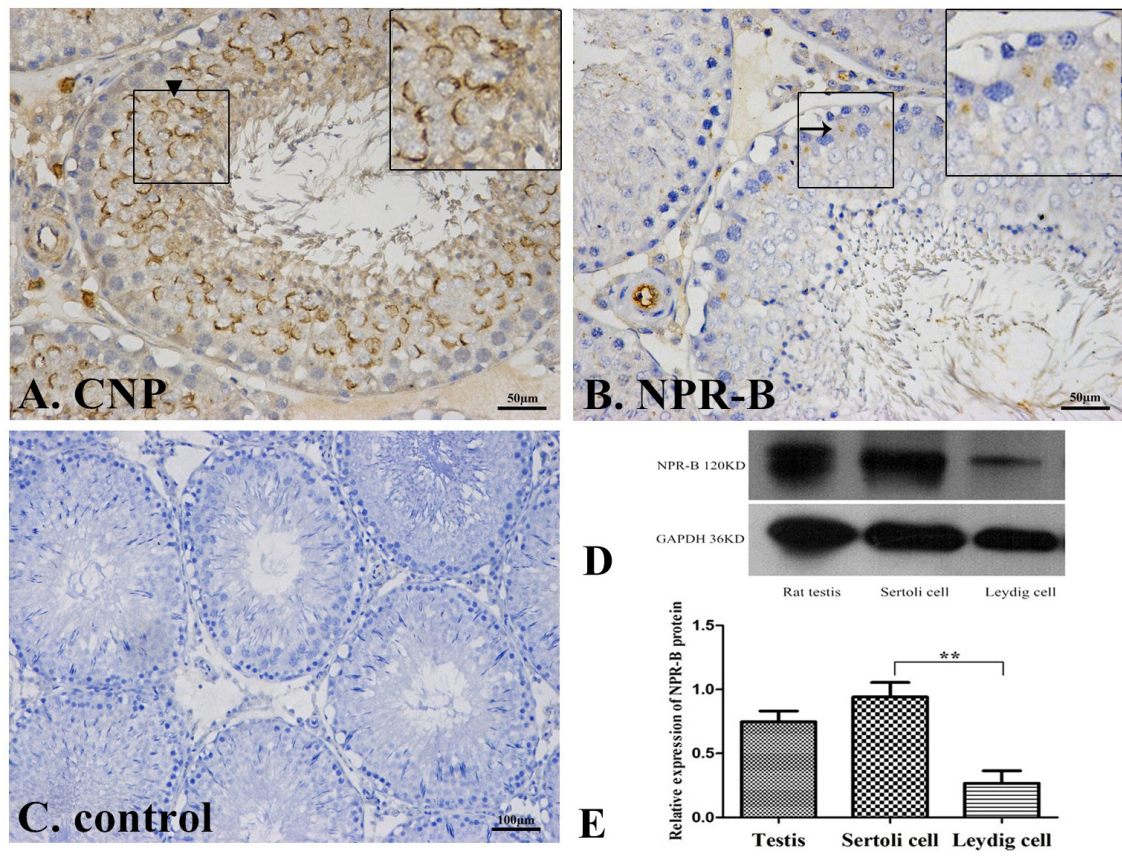

Table 2. Sequences of shRNA used in transfection experiments

\begin{tabular}{ll}
\hline Gene name & Sequence \\
\hline GI748769 & GCTGTGGACTGCTCCAGAACTTCTTAGTG \\
\hline GI748770 & ATCAACTGCTGAACCAGATGACAGTCATG \\
\hline GI748771 & GCCTTGACAGTGTCACTATCTACTTCAG \\
\hline GI748772 & CAACCTCTTGCTTCGCATGGAACAGTATG
\end{tabular}

\section{Statistical analysis}

All data were statistically analyzed using SPSS 23.0 software/Stata 21.0 software. The data shown are the mean \pm S.E.M. of at least three independent experiments. Each of the three to five independent experiments was run on a culture plate of Sertoli cells cultured in four to six replicates. Asterisks indicate significant differences $(P<0.05)$ among means, as estimated by the Mann-Whitney unpaired nonparametric two-tailed test (for two-point data experiments), Kruskal-Wallis test followed by Dunn's multiple comparison test (for group comparisons) or one-way ANOVA followed by the Student-Newman-Keuls multiple-range test (for group comparisons).

Figure 1. Expression of CNP and NPR-B in the normal rat testes.

(A-C) Immunostaining of CNP/NPR-B in the rat testes. (A) Immunostaining of CNP in rat testes showed that CNP was mainly localized in the germ cells (mostly spermatocytes) in the seminiferous epithelium and in the Leydig cells in the interstitium. (B) Immunostaining of NPR-B in the rat testes showed that NPR-B was mostly distributed in the Sertoli cells and vascular endothelial cells. (C) Negative control staining in the rat testes (primary antibody omitted). (D-E) The expression of NPR-B in different kinds of cells in the testes. (D) Western blot of NPR-B. (E) Relative expression level of NPR-B according to D. The Sertoli cells were shown to express more NPR-B than the Leydig cells $(P<0.01)$. NB: ${ }^{*} P<0.01$, triangle: spermatocyte, arrow: Sertoli cell. NB: ${ }^{*} P<0.05,{ }^{* *} P<0.01$. 

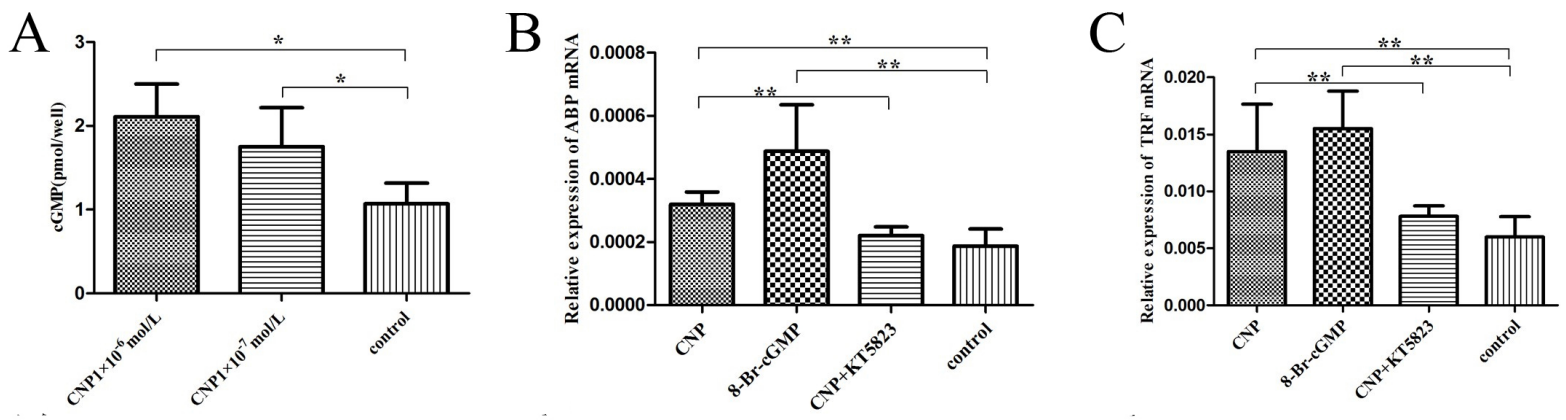

Figure 2. Dependence of CNP-induced ABP and TRF mRNA on the cGMP/PKG signaling pathway in Sertoli cells.

(A) Effect of CNP on CGMP accumulation in the Sertoli cells. (B-C) Relative expression of ABP and TRF mRNA in Sertoli cells in different groups. CNP groups: $1 \times 10^{-6} \mathrm{~mol} / \mathrm{L}$ CNP; 8 -bromo-cGMP groups: $1 \times 10^{-4} \mathrm{~mol} / \mathrm{L} 8$-bromo-cGMP; CNP + KT5823 groups: $1 \times 10^{-6} \mathrm{~mol} / \mathrm{L}$ CNP + $1 \times 10^{-6} \mathrm{~mol} / \mathrm{L}$ KT5823; control groups: culture medium.

\section{RESULTS}

\section{Expression of CNP and NPR-B in rat testes}

The immunohistochemical localization of CNP and NPR-B in rat testes is shown in Fig. 1A and B. Positive CNP staining was mainly localized in the germ cells (mostly spermatocytes) in the seminiferous epithelium and Leydig cells in the interstitium (Fig. 1A). However, its receptor, NPR-B, was mostly distributed in the Sertoli cells and vascular endothelial cells (Fig. 1B). The western blotting results further revealed that Sertoli cells and Leydig cells both expressed NPR-B (Fig. 1D), and Sertoli cells were shown to express more NPR-B than Leydig cells $(P<0.01$, Fig. 1E), suggesting that the Sertoli cells are the major cell type involved in the expression of NPR-B protein in the seminiferous epithelium.
cGMP/PKG signaling pathway participates in the CNPinduced expression of ABP and TRF MRNA in Sertoli cells

To investigate the effects of CNP on intracellular cGMP in Sertoli cells, cGMP levels in cultured Sertoli cells were measured using a cGMP ELISA kit after incubation with increasing concentrations of CNP. As shown in Fig. 2A, when we treated cells with $1 \times 10^{-7}$ $\mathrm{mol} / \mathrm{L} \mathrm{CNP}$ and $1 \times 10^{-6} \mathrm{~mol} / \mathrm{L} \mathrm{CNP}$, the cGMP levels of both groups were significantly higher than in the control group $(P<0.01)$. This result revealed that $\mathrm{CNP}$ could increase cGMP levels in Sertoli cells.

When compared with the control condition, supplementation with $1 \times 10^{-6} \mathrm{~mol} / \mathrm{L} \mathrm{CNP}$ and $1 \times 10^{-4} \mathrm{~mol} / \mathrm{L}$ 8 -bromo-cGMP in the culture medium has significantly increased gene expression of ABP and TRF in the cultured Sertoli cells, and this difference was statistically significant $(P<0.01$, Fig. $2 \mathrm{~B}$ and $2 \mathrm{C})$. This result is consistent with our previous research (Huang et al.,

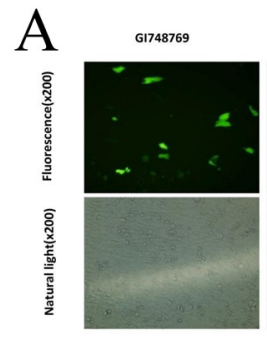

B

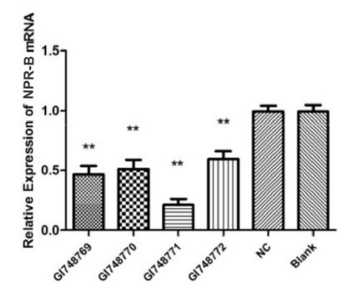

$\mathrm{D}$

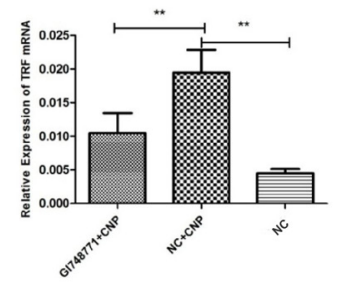

6178870
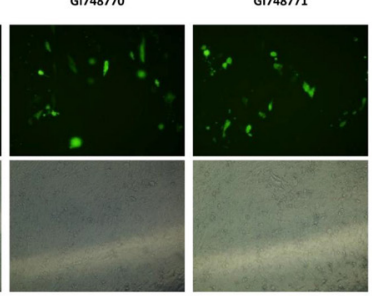

C

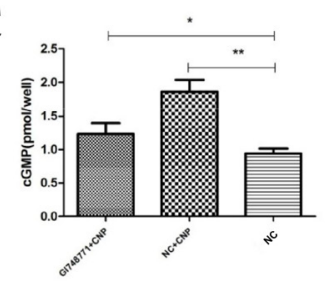

E
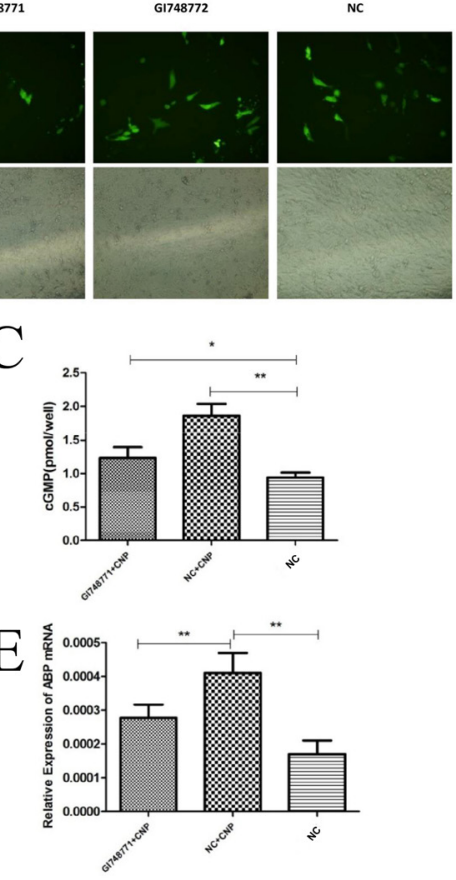

Figure 3. CNP induces ABP and TRF mRNA expression through NPR-B as evidenced by using shRNA silencing in TM4 cells.

(A) Transfection efficiency images of TM4 cells transfected with four different NPR-B shRNAs and the negative control group (NC). (B) Expression of NPR-B mRNA in transfected TM4 cells. (C) CGMP levels in cultured TM4 cells after $24 \mathrm{~h}$ incubation with $1 \times 10^{-6} \mathrm{~mol} / \mathrm{L}$ CNP. (D-E) Expression of ABP and TRF mRNA in cultured TM4 cells after $24 \mathrm{~h}$ of incubation with $1 \times 10^{-6} \mathrm{~mol} / \mathrm{L}$ CNP. NB: ${ }^{*} P<0.05{ }^{* *} P<0.01$. 


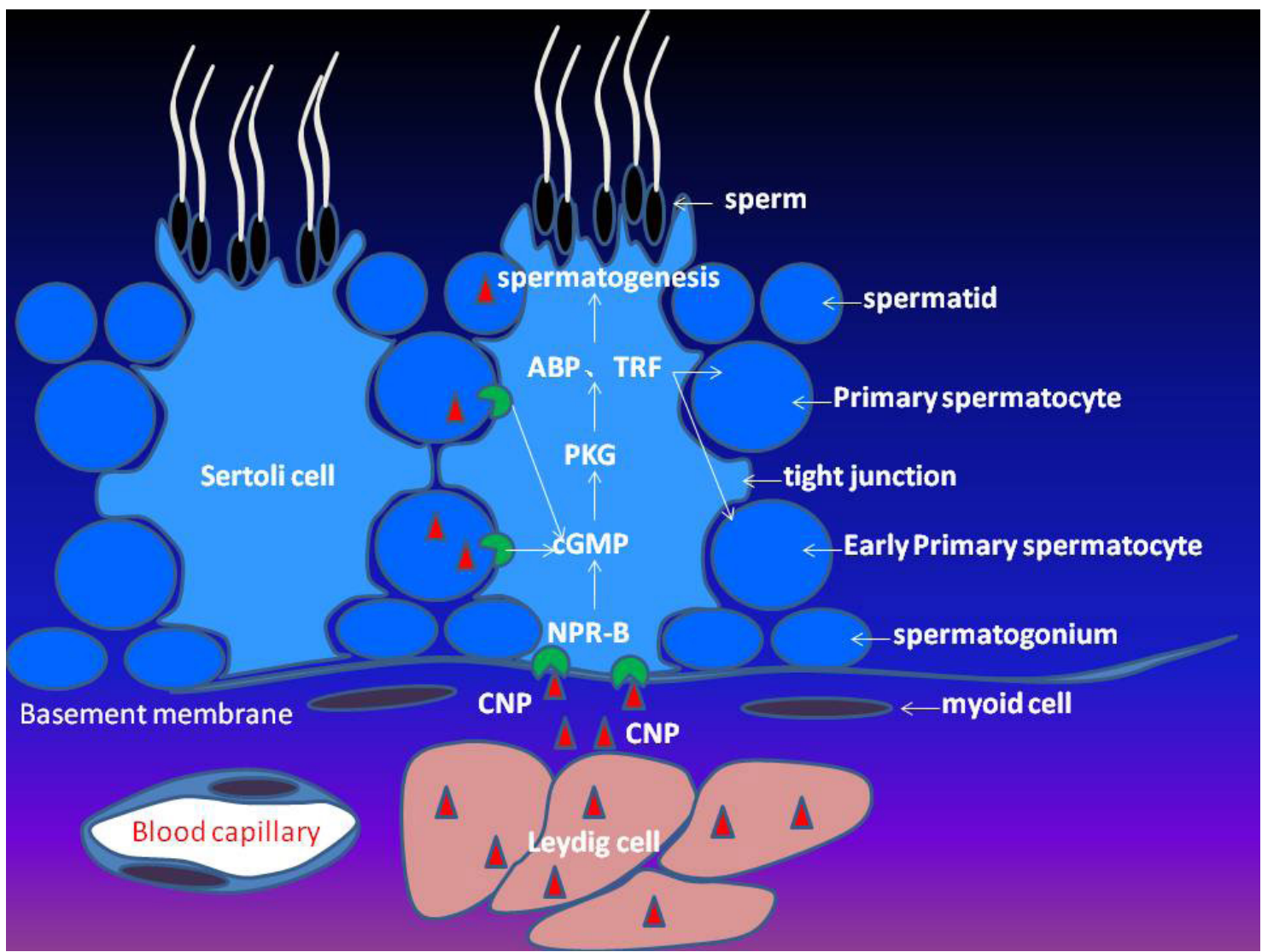

Figure 4. The signaling pathway of CNP in Sertoli cells.

CNP secreted by germ cells and Leydig cells can bind NPR-B in Sertoli cells, increase ABP and TRF gene expression through cGMP/PKG signaling, and regulate spermatogenesis. CNP: C-type natriuretic peptide; NPR-B: natriuretic peptide receptor B; ABP: androgen-binding protein; TRF: transferrin; cGMP: cyclic guanosine monophosphate; PKG: cGMP-dependent protein kinase.

2011). Furthermore, KT5823 markedly inhibited the CNP-induced increase in the $\mathrm{ABP}$ and TRF mRNA expression in Sertoli cells $(P<0.01$, Fig. $2 \mathrm{~B}$ and $2 \mathrm{C})$.

\section{Silencing the NPR-B gene attenuates the effect of CNP- induced expression of Abp and Trf mRNA in Sertoli cells}

To further clarify that CNP binds NPR-B to induce the expression of Abp and Trf mRNA, four different shRNAs were designed to transfect TM4 cells. The expression levels of NPR-B mRNA in TM4-transfected cells were analyzed by RT-PCR. The transfection efficiency images shown in Fig. 3A demonstrate that the transfection efficiency of the four shRNAs exceeded $50 \%$. When compared with the negative control (blank plasmid), all four Npr-b shRNAs could inhibit expression of Npr-b mRNA, especially GI748771 $(P<0.01$, Fig. 3B). Accordingly, we chose GI748771 to transfect TM4 cells for the 48 hour follow-up experiment.

The cGMP levels in cultured TM4 cells were measured after $24 \mathrm{~h}$ of incubation with $1 \times 10^{-6} \mathrm{~mol} / \mathrm{L}$ CNP. The amount of cGMP was significantly lower in the Npr-b silenced group than in the negative control group $(P<0.01)$; moreover, the cGMP content in the Npr-b silenced group was higher than that in the blank group $(P<0.05$, Fig. $3 \mathrm{C})$, which is probably due to the $50 \%$ transfection efficiency of Npr-b shRNA (Fig. 3C). This is also shown in the expression of Abp and Trf mRNA $(P<0.01$, Fig. 3D and $3 \mathrm{E})$.

\section{DISCUSSION}

The effects of CNP on reproductive function have recently drawn increased attention (Mirczuk et al., 2019). Recently, CNP was shown to play a critical role in reproduction (Guo et al., 2020; Wu et al., 2019), especially in the female reproduction (Zhang et al., 2010). However, the effects of CNP on male reproduction have only been reported in a few studies, although there are high expression levels of CNP in male reproductive organs (Nielsen et al., 2008 Chrisman et al., 1993). In our previous study, we found that CNP could significantly stimulate the endocrine function of the rat Sertoli cells, but its mechanism was unclear (Huang et al., 2011). This study demonstrated that CNP regulated the function of Sertoli cells via activation of the NPR-B/cGMP/PKG signaling pathway. To date, there have been no reports in the literature regarding the signaling pathway of CNP in testes. This study is the first to report that CNP plays its role through the NPR-B/cGMP/PKG signaling pathway in testes.

In the testis, O. Collin et al. reported that ANP was localized in spermatocytes and round spermatids within seminiferous tubules, while BNP and CNP were localized in the rat Leydig cells (Collin et al., 1997). A previous report has shown that natriuretic peptides could stimulate testosterone production in vivo, with significant effects at concentrations $\geq 1 \times 10^{-8} \mathrm{~mol} / 1$ of ANP, $\geq 1 \times 10^{-9} \mathrm{~mol} / \mathrm{L}$ of $\mathrm{BNP}$ and $\geq 1 \times 10^{-6} \mathrm{~mol} / \mathrm{L}$ of $\mathrm{CNP}$ (El-Gehani et al., 2001). Knockdown of NPR2 by RNAi 
resulted in S phase cell cycle arrest, cell apoptosis, and decreased testosterone secretion in the mouse Leydig cells (Yang et al., 2019). Xia and others (Xia et al., 2007) found that CNP was also expressed in a stage-specific manner and localized predominantly at the blood-testis barrier in the seminiferous epithelium at stage VIII of the epithelial cycle; however, its receptor, NPR-B, is distributed almost exclusively in the Sertoli cells. In our study, immunohistochemistry and western blotting methods were performed to determine the localization of CNP and NPR-B in rat testes. The results showed that CNP is mainly expressed in germ cells and Leydig cells but that its receptor, NPR-B, is mostly localized in the Sertoli cells and vascular endothelial cells. Indeed, our results are consistent with those reported in the previous literature. It is suggested that Sertoli cells may be the major cell type involved in the CNP/NPR-B signaling in the seminiferous epithelium.

According to previous studies, CNP can not only perturb the Sertoli cell tight junctions (Xia et al., 2007), but can also cause the Sertoli cells cultured in vitro to express Abp and Trf mRNA (Huang et al., 2011). In this experiment, shRNAs were used to silence Npr-b in a rat Sertoli cell line (TM4), and the results showed that Npr-b shRNAs could attenuate the effect of CNP-induced expression of Abp and Trf mRNA in Sertoli cells. Thus, we presumed that $\mathrm{CNP}$ promoted expression of Abp and Trf by binding NPR-B in Sertoli cells. Then, the cGMP signal was investigated in the Sertoli cells in the next experiment.

cGMP is an important intracellular second messenger. It promotes substrate protein phosphorylation to mediate a variety of biological effects mainly through the activation of its downstream signaling molecule, cGMPdependent protein kinase (PKG) (Tolone et al., 2019). Previous research demonstrated that cGMP was widely involved in the regulation of male reproductive functions, such as the development of germ cells (Sillaste et al., 2017), testosterone synthesis in the Leydig cells (Sokanovic et al., 2013), erection of the penis (Boydens et al., 2017), activation of sperm motility (Miraglia et al., 2011) and sperm capacitation (Cisneros-Mejorado et al., 2012). The early literature reported that PKG was expressed in the seminiferous epithelium of basal cells and was mainly localized in the Sertoli cells (Huang et al., 2007). Lee et al. found that nitric oxide synthase (NOS) is an important physiological regulator of the Sertoli cell tight junctions via the sGC/cGMP/PKG pathway (Lee et al., 2003). Li and others ( $\mathrm{Li}$ et al., 2017) found that carbon monoxide (CO) can activate the sGC signaling pathways to protect mouse Sertoli cells from hyperthermia-induced apoptosis. In this work, CNP increased the level of cGMP in Sertoli cells in a dose-dependent manner. 8-Bromo-cGMP exerts an obvious enhancing effect on the expression of Abp and Trf mRNA in Sertoli cells. The results indicated that CNP modulates the endocrine function of Sertoli cells by increasing intracellular cGMP levels. Furthermore, KT-5823, a specific inhibitor of PKG, was shown to remarkably inhibit the stimulatory effect of CNP on the expression of Abp and Trf mRNA in Sertoli cells, which indicated that CNP promotes expression of Abp and Trf via the cGMP/PKG pathway. In summary, we conclude that CNP is mainly synthesized and secreted by the Leydig cells and spermatogenic cells, and then binds to the specific receptor NPR-B in the cell membrane of Sertoli cells. It increases intracellular second messenger cGMP concentration and then activates the downstream signaling molecules' PKG activity to promote expression of $\mathrm{Abp}$ and Trf mRNA in the Sertoli cells to regulate spermatogenesis (Fig. 4). However, when performing immunohistochemical staining, a proper positive control was not included, and thus further studies are needed to include a positive control for immunohistochemistry to confirm our findings.

In summary, our study verified that CNP regulated expression of ABP and TRF mRNA in the murine Sertoli cells through the NPR-B/cGMP signaling. Our study was the first to investigated the role of cGMP signaling in the endocrine function of Sertoli cells. Next, we aim to further study the role of CNP in spermatogenesis.

\section{Declarations of interest}

None.

\section{REFERENCES}

An J, Li Y, Song S, Liu S (2019) Electroacupuncture promotes the gastrointestinal motility of diabetic mice by CNP/NPR-B-cGMP and PDE3A-cGMP signaling. Neurogastroenterol Motil 31: e13539. https:// doi.org/10.1111/nmo.13539.

Baba M, Yoshida K, Ieda M (2019) Clinical applications of natriuretic peptides in heart failure and atrial fibrillation. Int J Mol Sci 20: E2824. https://doi.org/10.3390/ijms20112824.

Boydens C, Pauwels B, Vanden Daele L, Van de Voorde J (2017) Inhibition of cyclic GMP export by multidrug resistance protein 4: a new strategy to treat erectile dysfunction? J Sex Med 14: 502-509. https://doi.org/10.1016/j.jsxm.2017.02.005.

Bükülmez H, Khan F, Bartels CF, Murakami S, Ortiz-Lopez A, Sattar A, Haqqi TM, Warman ML (2014) Protective effects of C-type natriuretic peptide on linear growth and articular cartilage integrity in a mouse model of inflammatory arthritis. Arthritis Rheumatol 66: 78-89. https://doi.org/10.1002/art.38199. doi: 10.1002/art.38199.

Chinta G, Ramya Chandar Charles M, Klopčič I, Sollner Dolenc M, Periyasamy L, Selvaraj Coumar M (2015) In silico and in vitro investigation of the piperine's male contraceptive effect: docking and molecular dynamics simulation studies in androgen-binding protein and androgen receptor. Planta Med 81: 804-812. https://doi. org/10.1055/s-0035-1546082.

Chrisman TD, Schulz S, Potter LR, Garbers DL (1993) Seminal plasma factors that cause large elevations in cellular cyclic GMP are C-type natriuretic peptides. J Biol Chem 268: 3698-703. PMID: 8094083

Cisneros-Mejorado A, Sánchez Herrera DP (2012) cGMP and cyclic nucleotide-gated channels participate in mouse sperm capacitation. FEBS Lett 586: 149-153. https://doi.org/10.1016/j.febslet.2011.12.006.

Collin O, Lissbrant E, Bergh A (1997) Atrial natriuretic peptide, brain natriuretic peptide and c-type natriuretic peptide: effects on testicular microcirculation and immunohistochemical localization. Int J Androl 20: 55-60. https://doi.org/10.1046/j.1365-2605.1997.00108.x.

Dietrich MA, Zmijewski D, Karol H, Hejmej A, Bilińska B, Jurecka P, Innazarow I, Slowińska M, Hliwa P, Ciereszko A (2010) Isolation and characterization of transferrin from common carp (Cyprinus carpio L) seminal plasma. Fish Shellfish Immunol 29: 66-74. https://doi. org/10.1016/j.fsi.2010.02.015.

El-Gehani F, Tena-Sempere M, Ruskoaho H, Huhtaniemi I (2001) Natriuretic peptides stimulate steroidogenesis in the fetal rat testis. Biol Reprod 65: 595-600. https://doi.org/10.1095/biolreprod65.2.595.

Guo L, He C, Mei C, Zhang L, Huang D (2020) Correlation analysis between $\mathrm{C}$ natriuretic peptide and pregnancy outcome. Am J Transl Res 12: 2007-2017. PMID: 32509195

Huang DH, Zhang SW, Zhao H, Zhang L (2011) The role of C-type natriuretic peptide in rat testes during spermatogenesis. Asian J Androl 13:275-80. https://doi.org/10.1038/aja.2010.147.

Huang DH, Zhao H, Tian YH, Xiong CL, Wang L (2007) Isolation, purification and identification of Sertoli cells from rat testes. Acta Anatom Sin 28: 246-249. https://doi.org/10.1016/S10018042(07)60062-1 (in Chinese)

Lee NP, Cheng CY (2003) Regulation of Sertoli cell tight junction dynamics in the rat testis via the nitric oxide synthase/soluble guanylate cyclase/3',5'-cyclic guanosine monophosphate/protein kinase $G$ signaling pathway: an in vitro study. Endocrinology 144: 3114-3129. https://doi.org/10.1210/en.2002-0167.

Li L, Li CM, Wu J, Huang S, Wang GL (2014) Heat shock protein 32/ heme oxygenase- 1 protects mouse Sertoli cells from hyperthermiainduced apoptosis by $\mathrm{CO}$ activation of sGC signalling pathways. Cell Biol Int 38: 64-71. https://doi.org/10.1002/cbin.10177.

Ma Y, Yang HZ, Xu LM, Huang YR, Dai HL, Kang XN (2015) Testosterone regulates the autophagic clearance of androgen binding 
protein in rat Sertoli cells. Sci Rep 5: 8894. https://doi.org/10.1038/ srep08894.

Miraglia E, De Angelis F, Gazzano E, Hassanpour H, Bertagna A, Aldieri E, Revelli A, Ghigo D (2011) Nitric oxide stimulates human sperm motility via activation of the cyclic GMP/protein kinase G signaling pathway. Reproduction 141: 47-54. https://doi.org/10.1530/ REP-10-0151.

Mirczuk SM, Lessey AJ, Catterick AR, Perrett RM, Scudder CJ, Read JE, Lipscomb VJ, Niessen SJ, Childs AJ, McArdle CA, McGonnell IM, Fowkes RC (2019) Regulation and function of C-type natriuretic peptide (CNP) in gonadotrope-derived cell lines. Cells 8: 1086. https://doi.org/10.3390/cells8091086.

Moghtadaei M, Polina I, Rose RA (2016) Electrophysiological effects of natriuretic peptides in the heart are mediated by multiple receptor subtypes. Prog Biophys Mol Biol 120: 37-49. https://doi. org/10.1016/j.pbiomolbio.2015.12.001.

Nielsen SJ, Gøtze JP, Jensen HL, Rehfeld JF (2008) ProCNP and CNP are expressed primarily in male genital organs. Regul Pept 146: 204 212. https://doi.org/10.1016/j.regpep.2007.09.022.

Prickett TC, Doughty RN, Troughton RW, Frampton CM, Whalley GA, Ellis CJ, Espiner EA, Richards AM (2017) C-Type natriuretic peptides in coronary disease. Clin Chem 63: 316-324. https://doi. org/10.1373/clinchem.2016.257816.

Sillaste G, Kaplinski L, Meier R, Jaakma Ü, Eriste E, Salumets A (2017) A novel hypothesis for histone-to-protamine transition in Bos taurus spermatozoa. Reproduction 153: 241-251. https://doi. org/10.1530/REP-16-0441.

Smith BE, Braun RE (2012) Germ cell migration across Sertoli cell tight junctions. Science 338: 798-802. https://doi.org/10.1126/science.1219969.

Sogawa C, Fujiwara Y, Tsukamoto S, Ishida Y, Yoshii Y, Furukawa T, Kunieda T, Saga T (2014) Mutant phenotype analysis suggests potential roles for $\mathrm{C}$-type natriuretic peptide receptor (NPR-B) in male mouse fertility. Reprod Biol Endocrinol 12: 64. https://doi. org/10.1186/1477-7827-12-64.

Sokanovic SJ, Baburski AZ, Janjic MM, Stojkov NJ, Bjelic MM, Lalosevic D, Andric SA, Stojilkovic SS, Kostic TS (2013) The opposing roles of nitric oxide and cGMP in the age-associated decline in rat testicular steroidogenesis. Endocrinology 154: 3914-3924. https:// doi.org/10.1210/en.2013-1307.
Sudoh T, Minamino N, Kangawa K, Matsuo H (1990) C-type natriuretic peptide (CNP): a new member of natriuretic peptide family identified in porcine brain. Biochem Biophys Res Commun 168: 863870. https://doi.org/10.1016/0006-291x(90)92401-k.

Tolone A, Belhadj S, Rentsch A, Schwede F, Paquet-Durand F (2019) The cGMP pathway and inherited photoreceptor degeneration: targets, compounds, and biomarkers. Genes (Basel) 10: 453. https://doi. org/10.3390/genes10060453.

Wu K, Mei C, Chen Y, Guo L, Yu Y, Huang D (2019) C-type natriuretic peptide regulates sperm capacitation by the cGMP/PKG signalling pathway via $\mathrm{Ca}^{2+}$ influx and tyrosine phosphorylation. Reprod Biomed Online 38: 289-299. https://doi.org/10.1016/j. rbmo.2018.11.025.

Xia C, Nguyen M, Garrison AK, Zhao Z, Wang Z, Sutherland C, Ma L (2013) CNP/cGMP signaling regulates axon branching and growth by modulating microtubule polymerization. Dev Neurobiol 73: 673-687. https://doi.org/10.1002/dneu.22078.

Xia W, Mruk DD, Cheng CY (2007) C-type natriuretic peptide regulates blood-testis barrier dynamics in adult rat testes. Proc Natl Acad Sci U S A 104: 3841-3846. https://doi.org/10.1073/ pnas.0610100104.

Yang L, Lei L, Zhao Q, Gong Y, Guan G, Huang S (2019) C-Type natriuretic peptide/natriuretic peptide receptor 2 is involved in cell proliferation and testosterone production in mouse leydig cells. World J Mens Health 37: 186-198. https://doi.org/10.5534/ wimh.180041.

Zenitani M, Nojiri T, Uehara S, Miura K, Hosoda H, Kimura T, Nakahata K, Miyazato M, Okuyama H, Kangawa K (2016) C-type natriuretic peptide in combination with sildenafil attenuates proliferation of rhabdomyosarcoma cells. Cancer Med 5: 795-805. https://doi. org/10.1002/cam4.642.

Zhang M, Su YQ, Sugiura K, Xia G, Eppig JJ (2010) Granulosa cell ligand NPPC and its receptor NPR2 maintain meiotic arrest in mouse oocytes. Science 330: 366-369. https://doi.org/10.1126/science.1193573.

Zhou PH, Hu W, Zhang XB, Wang W, Zhang LJ (2016) Protective effect of adrenomedullin on rat leydig cells from lipopolysaccharide-induced inflammation and apoptosis via the PI3K/ Akt signaling pathway ADM on rat leydig cells from inflammation and apoptosis. Mediators Inflammation 2016: 7201549. https://doi. org/10.1155/2016/7201549. 